\title{
Evaluation of Internal Egg Quality Traits of Japanese Quails (Coturnix Coturnix Japonicum) Supplemented With Varying Levels of Sargassum (Sargassum muticum)
}

Francisco F. Buctot Jr., Marry Connie S. Inso

Graduate School Southern Leyte State University Sogod, Southern Leyte

DOI: $10.36347 /$ sjet.2020.v08i08.004

| Received: 18.08.2020 | Accepted: 25.08.2020 | Published: 30.08.2020

*Corresponding author: Francisco F. Buctot Jr

\section{Abstract}

Original Research Article

Sargassum supplementation was evaluated on the effect of internal egg quality traits of Japanese quails at mid-late laying stage. There were three treatments and one control group. Each treatment and control group is replicated three times. The study was carried out in a complete randomized design (CRD). Results shows yolk weight at $15 \%$ supplementation got 4.63 grams, percent yolk ratio oranges from $39.39 \%$ to $46.44 \%$, yolk: albumen ratio at $15 \%$ was highest than the rest of the treatments. Yolk color manifested similar pale colors number 4 among treatments based on the Roche Yolk Color Fan instrument and albumen weight results was recorded heaviest weight (4.09 grams). Thus, significant differences were observed at $(p<0.05)$. Therefore, using pulverized sargassum as dietary supplement has economic potential and provides better internal egg quality traits at $15 \%$ supplementation.

Keywords: Yolk weight, yolk color, albumen weight, yolk index, and yolk ratio.

Copyright @ 2020: This is an open-access article distributed under the terms of the Creative Commons Attribution license which permits unrestricted use, distribution, and reproduction in any medium for non-commercial use (NonCommercial, or CC-BY-NC) provided the original author and source are credited.

\section{INTRODUCTION}

Quail is relatively easier to raise compared with chicken, as they require less nurturing because they are not susceptible to common poultry diseases. In order to produce quality quail eggs that are able to maintain high nutritional value and with egg shell strength for higher and faster return of investment, feed content and management of quails should be closely monitored [1].

Egg quality characteristics are influenced by many factors, including genetic and environmental factors. Quality traits of eggs determine the price directly in commercial flocks and it is usually described in connection with consumer's requirements. In meat line quails, the productivity and quality of eggs has been reported as an important factor for economic breeding and propagation of the flock [2].

Seaweed is reported to be a high ash content that can provide minerals and trace elements that are beneficial in both fertilizer and animal feed [3]. In coastal agricultural areas, the fresh plants are utilized as feed ingredients for hogs and cattle. Anecdotal reports indicated that fresh sargassum fed to farm animals produces bigger body mass of the animal but less fat
[4]. There are also a number of substances in seaweed species that have been found to have animal nutritional and health benefits [5]. In addition to feed for terrestrial animals, the macro alga sargassum has been extensively used for abalone aquaculture [6].

Sargassum muticum locally known as "samo" is one of the species of brown microalgae that is widely available in the coast of Sogod Bay. During high tide, it is brought and left scattered in the shoreline when the tide sets low. People in the area without minding their nutritional value, considered "samo" as a weed and therefore burn it during shoreline cleaning. Due to the high calcium requirements of commercial layers and of layer and broiler breeders, the knowledge on calcium sources that can supplement or be used in order to improve or to maintain performance and egg quality with the use of renewable calcium sources Hence, this study was conducted in order to establish internal egg quality traits and identify the effects of Japanese quails supplemented with varying levels of sargassum.

\section{METHODOLOGY \\ Experimental Design and Treatment}

A total of 60 heads of laying quails at 8 months old were used. The experimental bird was 
divided into three treatments and one control group with three replications each treatment and control group, which were carried out in a complete randomized design (CRD). In this study, pulverized sargassum was used as a feed supplement in the assigned treatments. According to the NRC (National Research Council) [7], the nutritional requirement for $\mathrm{Ca}$ is $2.5 \%$ for laying Japanese quails fed diets containing $2,900 \mathrm{kcal} / \mathrm{kg}$ while available $\mathrm{P}$ is $0.35 \%$. According to INRA (1999), Ca requirement in quails is 3.0 and $3.4 \%$ to the stage of egg production when feeding diets containing, 2,800 and $3,000 \mathrm{kcal} / \mathrm{kg}$ respectively. The nutritive utilization of calcium by laying poultry is highly effective. It has been shown that what determine the best assimilation of the aforementioned mineral are the intensity of egg lying, and, specifically the process of the formation of the egg shell. The findings of the study of Amoah et al. [8] on Calcium and phosphorus requirements of Japanese quail layers indicated that improvement in performance of quails in both early and post peak production period can be achieved with dietary calcium level higher than the $2.5 \%$ recommended by the NRC [7]. The table below shows the following treatments used in the study:

Table-1: Four treatments of the layer quails supplemented with varying levels of sargassum powder

\begin{tabular}{|l|l|}
\hline T0 & $100 \%$ commercial feeds \\
\hline T1 & $95 \%$ commercial feeds $+5 \%$ pulverized Sargassum muticum \\
\hline T2 & $90 \%$ commercial feeds $+10 \%$ pulverized Sargassum muticum \\
\hline T3 & $85 \%$ commercial feeds $+15 \%$ pulverized Sargassum muticum \\
\hline
\end{tabular}

In measuring the egg quality, 3 eggs per replicate were collected every 7 days for four consecutive days for a total period of 28 days. A completely randomized experimental design was applied, with 4 treatments $(0,5,10$, and $15 \%)$ inclusion of sargassum powders, including a total number of 36 eggs per treatment, and a total number of 144 eggs.

From the nutritional point of view minerals are among the most important ingredients composing 5\% animal body. Thus, the level of inclusion 5, 10and 15\% were used in the study. According to McDowell [14], among all minerals, calcium and phosphorus stand out as they contribute to making up a large portion of animal skeleton ( 80 to $85 \%$ ), and also participate in the formation of egg and muscle structure, thus being essential for the proper functioning of animal body

\section{Preparation of pulverized Sargassum muticum powder}

In order to produce pulverized sargassum, the Sargassum muticum was collected from the shoreline of the Sogod Bay Area. The collected samples were thoroughly washed and dried for three days with $80.99 \%$ DM and $18.77 \%$ moisture content. It was pulverized using a mortar and pestle.

\section{Management Practices}

Standard management practices in preparation of the experimental cages, rearing management, disease prevention, control, and practices were adopted during the conduct of the experiment or until it was terminated. Water and feed were offered "ad libitum", and feed intake and egg weight were weekly determined. Birds were submitted to 12 hours of light daily. Eggs were collected daily, in the morning.

\section{Data Gathering}

Prior to the actual conduct of the study the weight of the quail is recorded. Feed consumption was determined by weighing the feed given and the orts for 28 days. Mortality was also recorded.

The following parameters were adopted from the study of Buctot Jr. and Espina, [12].

\section{Internal egg traits of quails}

A. Yolk diameter was measured using a digital Vernier caliper.

B. Yolk Height was measured using a digital Vernier caliper.

C. Yolk weight was measured using a digital analytical balance

D. Yolk $\mathrm{pH}$ was measured a digital $\mathrm{pH}$ meter

E. Yolk color was measured using the Roche Yolk Color Fan.

$F$. Percent yolk index was measured by dividing the yolk height by the yolk diameter multiplied by 100 .

G. Percent yolk ratio was measured by dividing the yolk weight by the egg weight multiplied by 100 .

H. Albumen height was measured using a digital Vernier caliper.

I. Albumen weight was measured using a digital analytical balance

J. The albumen: yolk ratio was measured by dividing the yolk weight by the albumen weight.

\section{DATA ANALYSIS}

The experimental data gathered were analyzed using one-way analysis of variance (ANOVA). Significant differences among treatment means were determined using Tukey's Honestly Significant Difference. 


\section{RESULTS AND DISCUSSIONS}

The result in Table 2 shows the internal egg quality traits of quails supplemented with varying levels of sargassum powder. Results revealed that supplementation of sargassum affects the yolk weight, $\%$ yolk ratio and yolk: albumen ratio of the quail eggs. Thus, significant differences were observed at ( $p$ $<0.05)$.
Yolk weight at $15 \%$ supplementation of sargassum got 4.63 grams which is the highest, followed by $10 \%, 5 \%$, and $0 \%$ supplementation (Figure 1). Moreover, there is an inversely proportional relationship between the yolk weight and the percentage of supplementation of sargassum was observed. This due to the fact that egg yolk is a vital resource of nutrients and the primary storage site of trace minerals for the embryos and hatchlings. This supports the concept that larger eggs result larger chicks due to the better nutritional conditions of the embryos [9].

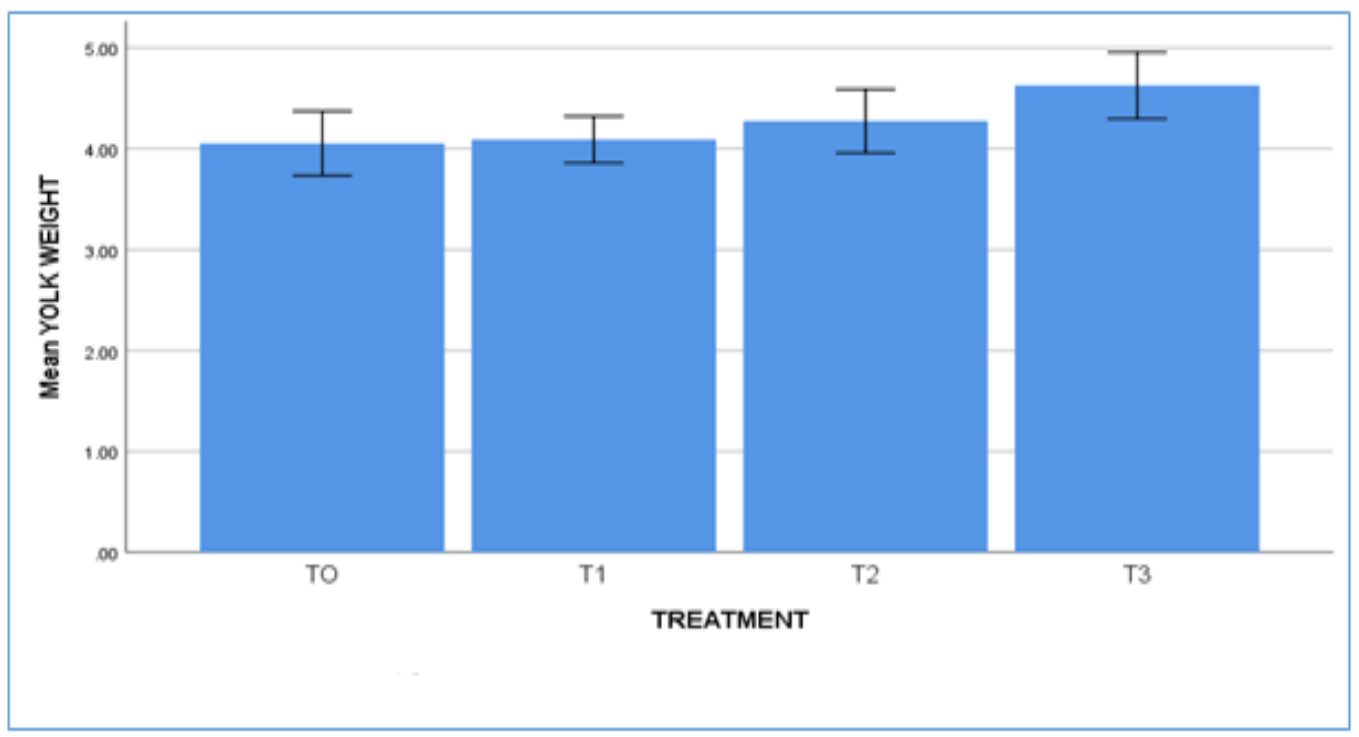

Fig-1: Bar graph of yolk weight quail supplemented with sargassum powder error bares $95 \% \mathrm{CI}$

Percent yolk ratio of quails supplemented with sargassum ranges from $39.39 \%$ to $46.44 \%$. This signified that the level of sargassum supplement at $15 \%$ has a direct effect to the yolk weight and egg weight of quail eggs (Figure 2). In addition of their functional importance, these parameters are typically used to determine egg quality from several points of view, including egg nutritional content, egg integrity for commercialization, storage and incubation, as well as preservation during storage. The yolk and the albumen are the main organic components of the egg, supplying 32 and $1 \%$ of fat and 16 and $11 \%$ of protein, respectively [10].

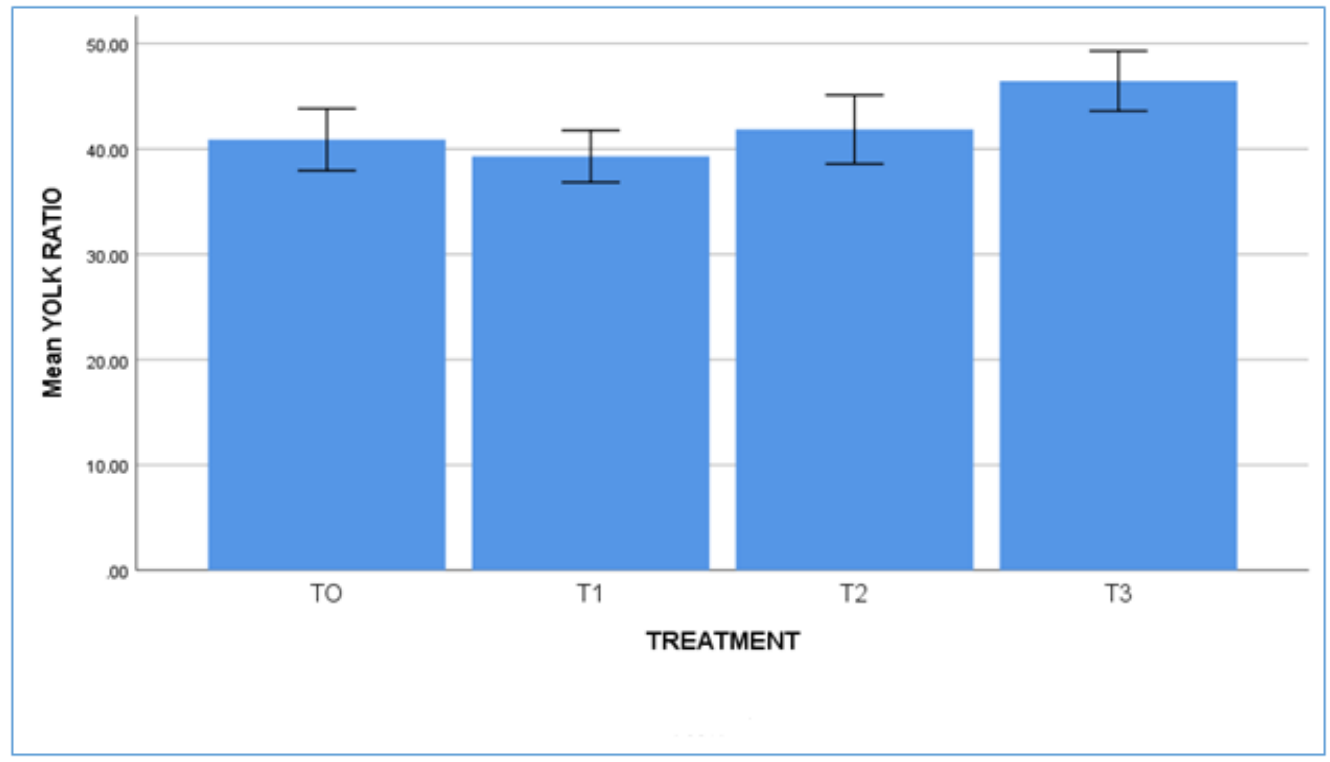

Fig-2: Bar graph of \% yolk ratio of quail supplemented with sargassum powder 
Yolk: albumen ratio results found out that $15 \%$ sargassum powder supplement was highest in percentage than the rest of the treatments (Figure 3 ). This signified that a higher the level of sargassum greatly affected the yolk albumen ratio of the quail's egg. The varied percentages of albumen weight and yolk weight might come from the genetic make-up of the birds, nutrition and management and laying period [11].

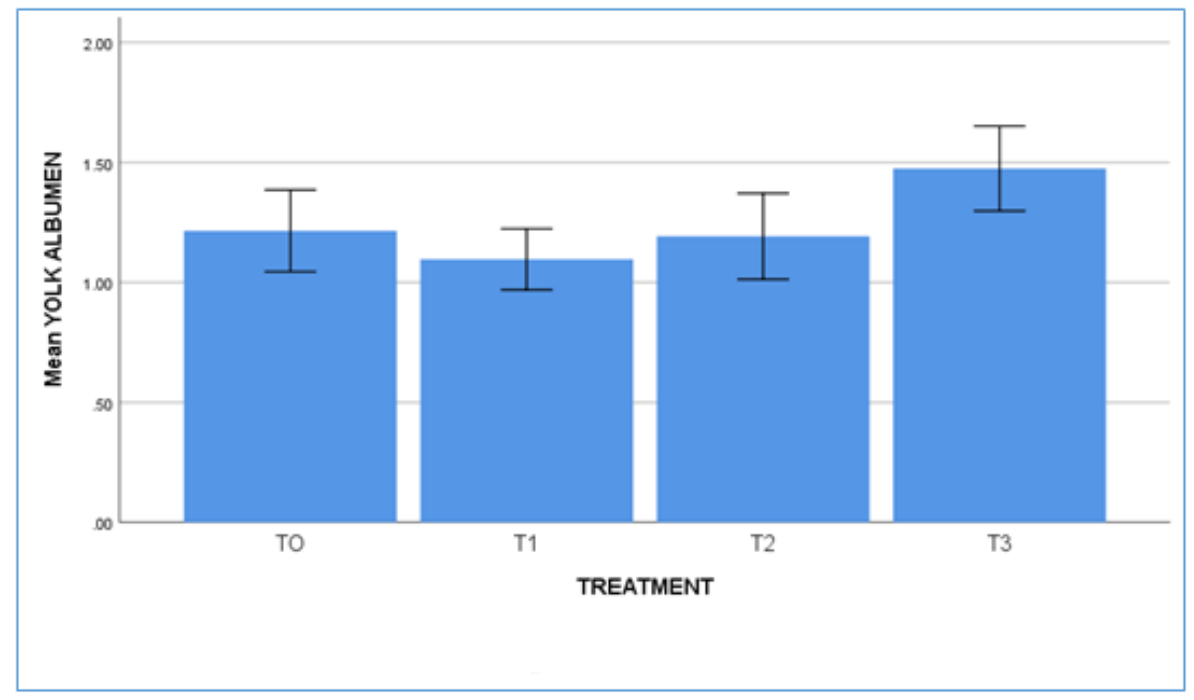

Fig-3: Bar graph of \% yoik albumen ratio of quail supplemented with saragassum powder error bars:95\% ci

Yolk Color in Figure 4, manifested similar pale colors number 4 among treatments based on the Roche Yolk Color Fan instrument. Yolk color could be affected by the type of diet given to the experimental birds [12]. This supports the study of North (1984) that there are factors that affect yolk color, and one is the ingredients of the ration. This means that sargassum powder has a comparable effect to commercial feeds in terms of yolk color.

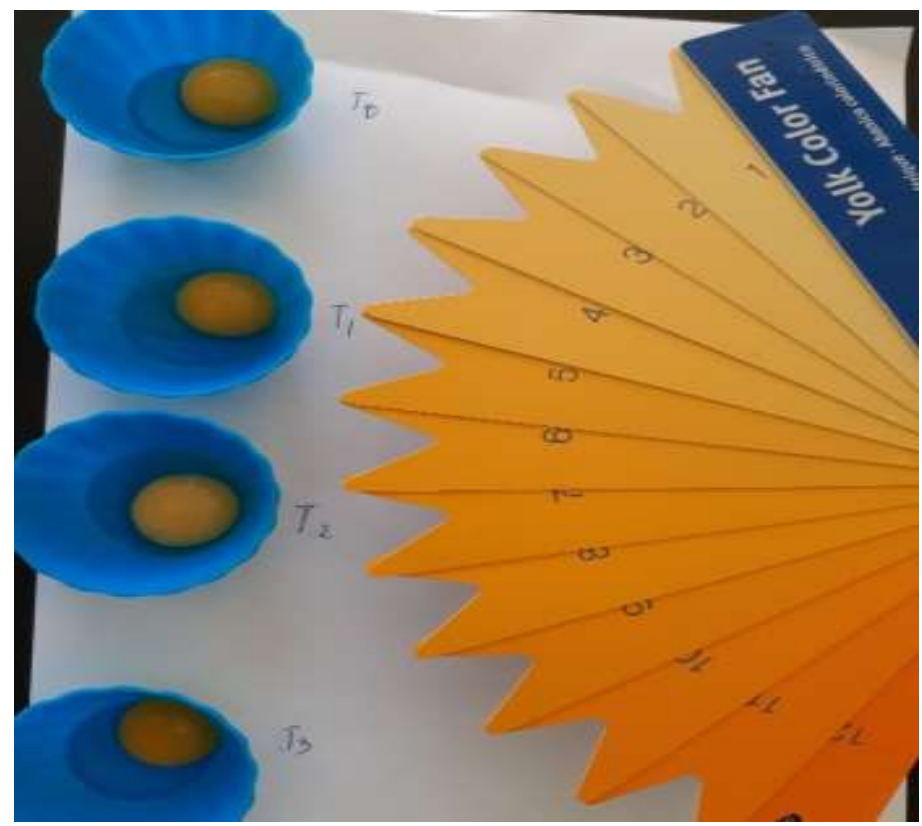

Fig-4: Yolk color determination using Roche Yolk Color Fan of quail egg supplemented with varying levels of sargassum powder

Albumen weight results revealed that 5\% supplementation of sargassum powder was recorded with the heaviest weight (4.09 grams). This was followed by $10 \%$ of sargassum powder, pure commercial feeds, and $15 \%$ sargassum powder (Figure 5). It is evident that the inclusion of sargasum powder in the diet of quail has a direct effect on the albumen weight and follows the same trend as to the egg weight. This was due to the most intensive physical and chemical changes and processes occurring during the storage time [13]. 


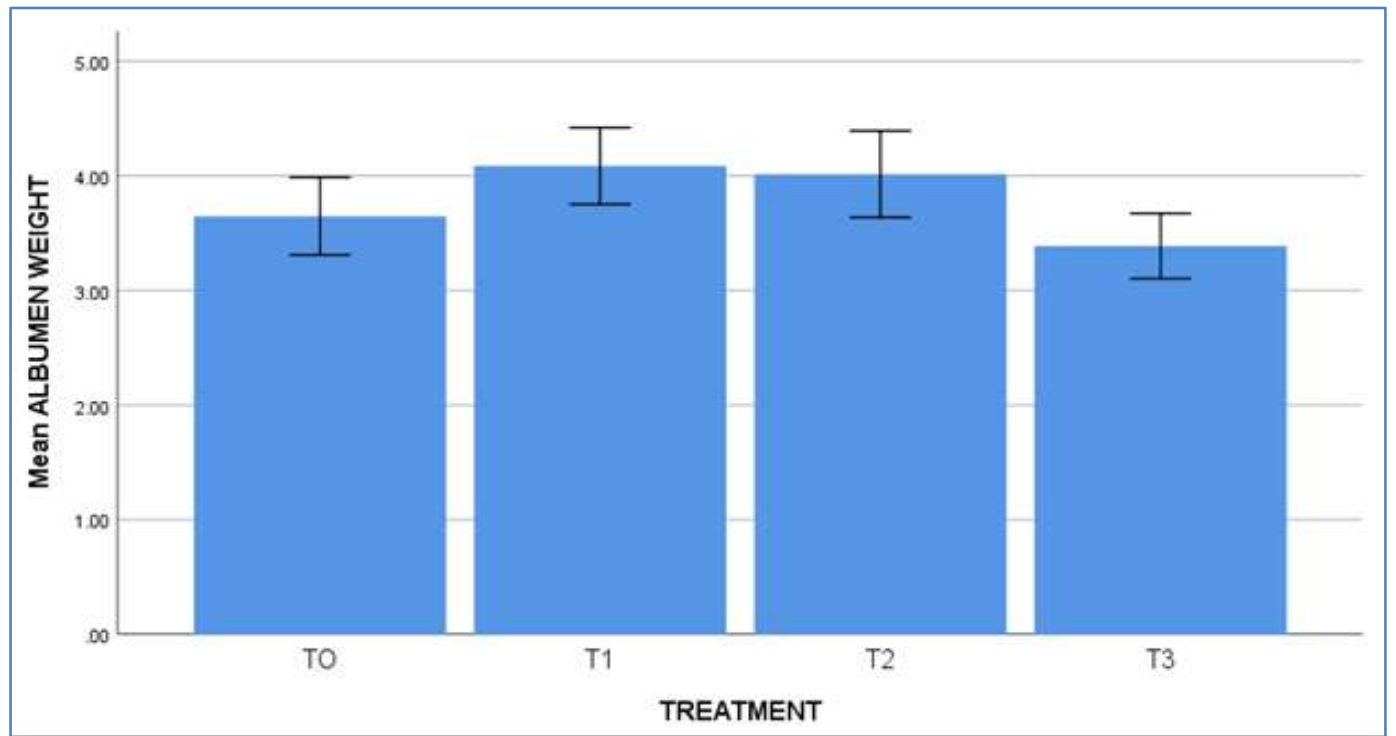

Fig-5: Bar graph of albumen weight of quail supplemented with saragassum powder error bars:95\%ci

On the other hand, the results of yolk diameter, yolk height, yolk $\mathrm{pH}$ and albumen height shows no significant differences among treatments at $(p<0.05)$.
Although not significant but the supplementation of Sargassum powder at varying levels is still comparable with the quail fed with commercial diet.

Table-2: Internal egg quality traits of quail supplemented with varying levels of sargassum powder

\begin{tabular}{|c|c|c|c|c|c|}
\hline $\begin{array}{l}\text { Internal Egg Quality } \\
\text { Traits }\end{array}$ & $\begin{array}{l}\text { T0(commercial } \\
\text { feeds) }\end{array}$ & $\begin{array}{l}\mathrm{T} 1(5 \% \\
\text { supplement })\end{array}$ & $\begin{array}{l}\mathrm{T} 2(10 \% \\
\text { supplement) }\end{array}$ & $\begin{array}{l}\text { T3(15\% } \\
\text { supplement) }\end{array}$ & p value \\
\hline Yolk diameter $(\mathrm{mm})$ & 24.75 & 25.84 & 25.90 & 24.90 & $0.184 \mathrm{~ns}$ \\
\hline Yolk Height (mm) & 2.63 & 2.84 & 2.99 & 3.12 & $0.133 \mathrm{~ns}$ \\
\hline Yolk weight (g) & $4.05^{b}$ & $4.09^{\mathrm{ab}}$ & $4.27^{\mathrm{ab}}$ & $4.63^{\mathrm{a}}$ & 0.028* \\
\hline Yolk pH $\left({ }^{0} \mathrm{C}\right)$ & 6.63 & 6.66 & 6.63 & 6.69 & $0.933 \mathrm{~ns}$ \\
\hline Yolk Color & 4 & 4 & 4 & 4 & \\
\hline Yolk index $(\%)$ & 10.94 & 11.21 & 11.92 & 12.92 & $0.244 \mathrm{~ns}$ \\
\hline Yolk Ratio(\%) & $\mathbf{4 0 . 8 8}^{\mathrm{b}}$ & $39.39^{b}$ & $41.84^{\mathrm{ab}}$ & $46.44^{\mathrm{a}}$ & 0.004 \\
\hline Albumen Height (mm) & 1.28 & 1.53 & 1.37 & 1.25 & $0.301 \mathrm{~ns}$ \\
\hline Albumen weight (g) & $3.65^{\mathrm{ab}}$ & $4.09^{a}$ & $4.01^{a}$ & $3.39^{b}$ & $\mathbf{0 . 0 1 0} * *$ \\
\hline Yolk:albumen ratio & $1.22^{\mathrm{ab}}$ & $1.10^{b}$ & $1.19^{\mathrm{ab}}$ & $1.47^{\mathrm{a}}$ & $0.009 * *$ \\
\hline
\end{tabular}

Column means without common superscripts are significantly different $(\mathrm{p}<0.05)$

**highly significant $(p<0.01)$

*significant $(p<0.05)$

${ }^{\mathrm{ns}}$ Not significantly different $(p>0.05)$

\section{CONCLUSION AND RECOMMENDATION}

Supplementing sargassum powder at optimum level of supplementation of $15 \%$ have positive effect on the internal egg quality traits of quail egg particularly the yolk weight, percent yolk ratio and yolk:albumen ratio and the production performance.. Therefore, supplementation of sargassum powder from $5 \%$ up to $15 \%$ have positive effects on the performance of quail particularly at mid-late laying stage.

It is recommended that nutrient analysis of quail egg fed with sargassum powder supplement is conducted in order to validate if there is a positive or negative effect on the nutritional composition of the egg and conduct related studies to other poultry species in order to further discover the potentials of sargassum as feed supplement.

\section{REFERENCES}

1. Bejar FR. Growth and Reproductive Performance of Quail Fed with Varying Levels of Trichanthera gigantea Nees. Leaf meal supplemented with aloe vera extract and acid cheese whey in drinking water. Thesis .Samar State College of Agriculture and Forestry.2017.

2. Punya Kumaril B, Ramesh Gupta B, Gnana Prakash M, Rajasekhar Reddy A. A study of egg quality traits in Japanese quails. J Veterinary and Anim Sci. 2008;4(6):227-31.

3. Philippsen A. Energy input, carbon intensity, and cost for ethanol produced from Brown Seaweed. University of Victoria, Victoria. 2013. retrieve online DOI 10.1007/s11157-015- 9381-7

4. Montano MN, Rodriguez MR, Balitaan RL. Ethnobotany of Sargassum spp. in the Philippines. 
Coastal Marine Science Journal. 2006 Apr 28;30(1):222-5.

5. Sweeney T, Meredith H, Vigors S, McDonnell MJ, Ryan M, Thornton K, O’Doherty JV. Extracts of laminarin and laminarin/fucoidan from the marine macroalgal species Laminaria digitata improved growth rate and intestinal structure in young chicks, but does not influence Campylobacter jejuni colonisation. Animal Feed Science and Technology. 2017 Oct 1;232:71-9.

6. Dang VT, Li Y, Speck P, Benkendorff K. Effects of micro and macroalgal diet supplementations on growth and immunity of greenlip abalone, Haliotis laevigata. Aquaculture. 2011 Oct 19;320(1-2):91-8.

7. NRC (National Research Council). Nutrient requirements of poultry. .Nutrient Requirements of Domestic Animals. 9th rev. ed . Natl. Acad. Sci., Washington, D.C. 1994.

8. Amoah JK, Martin EA, Barroga AJ, Garillo EP, Domingo I. Calcium and phosphorus requirements of Japanese quail layers. Journal of Applied Biosciences. 2012;54:3892-900.

9. Zita L, Ledvinka Z, Tumova E, Klesalova L. Technological quality of eggs in relation to the age of laying hens and Japanese quails. Revista Brasileira de zootecnia. 2012 Sep;41(9):2079-84.

10. Willems E, Decuypere E, Buyse J, Everaert N. Importance of albumen during embryonic development in avian species, with emphasis on domestic chicken. World's Poultry Science Journal. 2014 Sep 1;70(3):503-18.

11. Hussein T, Urge M, Animut G. Effect of replacing soybean meal (Glycine max) with kidney bean (Phaseolus vulgaris) on egg quality parameter of white Leghorn layers. International Journal of Livestock Production. 2016 Jun 30;7(6):33-40.

12. Buctot Jr FF, Espina DM. Breeding Performance and Egg Quality of Red Jungle Fowl (Gallus gallus L.) Under Confinement System. Journal of Science, Engineering and Technology. 2015 Dec 31;3:6575.

13. Adamski M, Kuźniacka J, Kowalska E, KucharskaGaca J, Banaszak M, Biegniewska M. Effect of storage time on the quality of japanese quail eggs (Coturnix coturnix japonica). Pol. J. Nat. Sci. 2017;32(1):27-37.

14. Mcdowell LR. Calcium and phosphorus. Minerals in animal and human nutrition. 1992. 